\title{
Evaluation of Pulmonary Impairment by Spirometry in Post Pulmonary Tuberculosis Patients
}

\author{
Authors \\ Santhosh Kumar P.V ${ }^{1}$, Lisha P. $\mathbf{V}^{\mathbf{2}}$ \\ ${ }^{1}$ Associate Professor, ${ }^{2}$ Senior Resident \\ Dept. of Pulmonary Medicine, Institute of Chest Diseases, Medical College, Calicut \\ Email:drpvsk@ rediffmail.com
}

\begin{abstract}
Background: Tuberculosis has been stated as a risk factor for development of COPD in the GOLD guidelines. It is important to know the relative burden of lung function impairment brought about by tuberculosis because there is a high prevalence of tuberculosis and smoking in the country

Aim of the Study: Toanalyze the spirometric abnormalities in a cohort of post tuberculosis patients

To know the factors associated with the spirometric abnormalities

Study Method: The study was conducted in the Dept of Pulmonary Medicine, Govt Medical College, Kozhikode in the period between 2009 and 2013. An analysis of records maintained under RNTCP is made. All new sputum smear positive cases during the period 2002 to 2006 who had completed 5 years after their treatment for smear positive tuberculosis were identified and called to the OPD. History, physical examination and investigations including chest X-ray, sputum AFB smear and spirometry was done in all patients.

Results: A total of 82 patients were available for final analysis. The age of the patients ranged from 24 to 80 years and mean age was 51.29. 74 (90.2\%) were males and $8(9.8 \%)$ were females. At 5 years after treatment completion 61 (74.4\%) were symptomatic and 21 (25.6\%) were asymptomatic. Radiological sequelae were present in 54 (65.9\%) patients.59 (72\%) patients were smokers $23(28 \%)$ were nonsmokers. Spirometry revealed obstructive pattern in 37 patients (45.1\%), restrictive pattern in 21 patients (25.6\%). it revealed a mixed pattern or normal results in 24 patients (29.3\%).

Conclusion: Abnormal spirometry was found in $58(70 \%)$ patients. Obstructive pattern was the most common abnormality. Restrictive pattern was the main abnormality in nonsmokers. Presence of radiological sequelae correlated with the presence of spirometric abnormality. The obstructive pattern showed significant association with presence of radiologic sequelae,smoking and persistent chest symptoms after completion of ATT.
\end{abstract}

\section{BACKGROUND OF THE STUDY}

Tuberculosis remains a worldwide public health problem despite the fact that the causative organism was discovered more than hundred years ago and highly effective drugs are available making it a curable disease. As of now TB (tuberculosis) is one of the most challenging communicable diseases to control effectively. More than 2 billion, that is, one-third of the world's population is infected with the tubercle bacillus $^{1}$. Someone in the world is newly infected with tuberculosis bacilli every second. An estimated 1.3 million people died from tuberculosis in $2009^{2}$. Even after successful 
treatment the patents continue to suffer from varying sequelae of the disease. Tuberculosis has been found to cause obstructive or restrictive lung function abnormalities in about 40 to $60 \%$ people who suffer sequelae of tuberculosis ${ }^{3}$. Also other risk factors like smoking and poor socioeconomic status are widely associated with tuberculosis. Tuberculosis has been stated as a risk factor for development of COPD in the GOLD guidelines ${ }^{4}$. It is important to know the relative burden of lung function impairment brought about by tuberculosis because there is a high prevalence of tuberculosis and smoking in the country

\section{MATERIALS AND METHODS Study population}

All patients who had taken Category 1 ATT under RNTCP for New smear positive pulmonary tuberculosis five years before are included in the study.

Study period

November 2009 to May 2013

\section{Inclusion criteria}

All new sputum smear positive cases registered at the RNTCP center at ICD during the period from 2001 to 2004 are included and these patients are followed up so as to know their status 5 years after treatment.

Those patients who were on follow up at the Department who had treatment records from RNTCP showing they had taken Category 1 treatment for smear positive pulmonary tuberculosis during the period 2002 to 2006 were also included in the study

Acceptable spirometry results

\section{Exclusion criteria}

All smear negative pulmonary and extra pulmonary cases are excluded from the study.

All cases transferred out of state are excluded from the study.

All patients who cannot be traced are excluded from the study [eg, patients in temporary dwellings like gypsies].

\section{Study design}

Cross Sectional study

\section{Method}

An analysis of records maintained under RNTCP is made. All new sputum smear positive cases during the period 2002 to 2005 are identified. Cases are contacted by sending letters in envelope to maintain confidentiality. Those people who respond to the letters are advised to attend the Out Patient Department. Those patients who were already on follow up in the Department, who had previous treatment records from RNTCP showing they had taken Category 1 treatment for smear positive pulmonary tuberculosis during the same period were also included in the study. When these patients visited the OPD, they were evaluated by a detailed medical history including present symptoms, past history, family history contact with smear positive case and personal history - addictions including smoking and alcoholism, occupation and annual income. Physical examination was done and clinical diagnosis was made. Investigations included Hemoglobin, TC, DC, ESR, and RBS in all patients. Chest $\mathrm{X}$ - ray was done in all patients. Sputum AFB smear examination was done in all patients. FBS/PPBS, Renal Function Test, Liver Function Test and ECG were done in selected cases. Sputum AFB culture, spirometry, bronchoscopy and CT Thorax if required.

\section{Classification of radiological lesions}

The radiological lesions were classified in to three groups.

Class 1 - Minimal lesions

Lesions of limited extend and slight or moderate density, either unilateral or bilateral that involve an area not greater than that contained by the space between the apex of lung to second costal cartilage or the body of the fifth thoracic vertebra. Lesions should not include demonstrable cavitation.

Class 2 - Moderately advanced This consists of lesions of slight to moderate density involving the area occupied by one lung. If the lesions are dense then the area should be limited to one-third of a lung. The lesions may be unilateral or bilateral. 
Total diameter of cavitation should be less than 4 cms.

\section{Class 3 - Far advanced}

This signifies involvement in excess of the above.

\section{Spirometry}

Spirometry was done using micro Quark PC based turbine type spirometer by Cosmed. The parameters were analyzed according to the guidelines of $\mathrm{ATS}^{5}$. Obstructive pattern was taken as FEV1/ FVC ratio of less than 0.7. Spirometry was performed in all patients at first visit. Acceptable reports were included in analysis.

\section{STATISTICAL ANALYSIS}

Statistical analysis was done using SPSS software version 12.0. The Chi-square test was used for testing the difference in the proportions. Univariate analysis was performed to find the distribution of factors among patients who had sequelae, relapse and those who had died. Odds ratio (OR) and $95 \%$ confidence intervals $(95 \% \mathrm{CI})$ were calculated. In multivariate analysis, significant factors were included to find independent association of factors with outcomes adjusting for confounding factors. $\mathrm{P}$ value $>0.05$ was considered statistically significant. Continuous variables were tested using student $\mathrm{T}$ test.

\section{RESULTS}

A total 742 patients were identified as new smear positive patients registered for Category 1 treatment at the Institute of Chest Diseases. Of these 202 patients attended the OPD. 22 patients who attended the OPD, who had the RNTCP treatment cards showing they had taken Category1 treatment under RNTCP from various tuberculosis units during the period from 2002 to 2004 were also included in the study.
Figure 1 - Age distribution

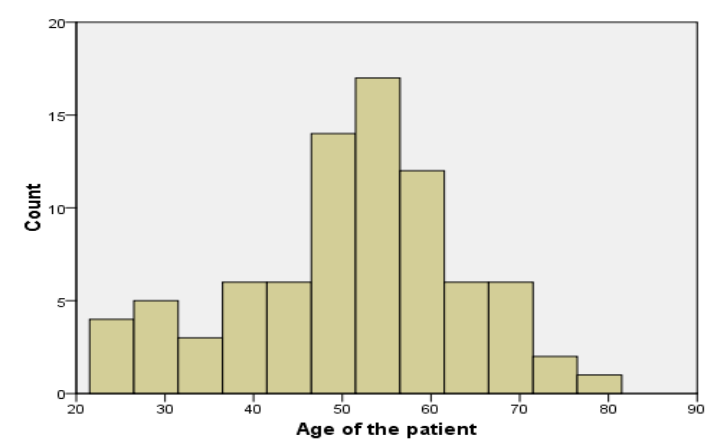

Table 1 - Gender and spirometry

\begin{tabular}{|c|c|c|c|c|}
\hline Spirometry & Obstructive & Restrictive & Normal & Total \\
\hline Male & $36(43.9 \%)$ & $\begin{array}{c}17 \\
(20.7 \%)\end{array}$ & $\begin{array}{c}21 \\
(25.6 \%)\end{array}$ & $\begin{array}{c}74 \\
(90.2 \%)\end{array}$ \\
\hline Female & $1(1.2 \%)$ & $4(4.9 \%)$ & $\begin{array}{c}3 \\
(3.7 \%)\end{array}$ & $\begin{array}{c}8 \\
(9.8 \%)\end{array}$ \\
\hline
\end{tabular}

Table 2 -Smoking and spirometry

\begin{tabular}{|c|c|c|c|c|}
\hline & Obstructive & Restrictive & Normal & Total \\
\hline Smoking & $34(41.5 \%)$ & $11(13.4 \%)$ & $\begin{array}{c}14 \\
(17.1 \%)\end{array}$ & $\begin{array}{c}59 \\
(72 \%)\end{array}$ \\
\hline $\begin{array}{c}\text { Non } \\
\text { smoking }\end{array}$ & $3(3.7 \%)$ & $10(12.2 \%)$ & $\begin{array}{c}10 \\
(12.2 \%)\end{array}$ & $\begin{array}{c}23 \\
(28 \%)\end{array}$ \\
\hline
\end{tabular}

Table 3 -Presence of radiological sequelae and spirometry

\begin{tabular}{|l|l|l|l|l|}
\hline & Obstructive & Restrictive & Normal & Total \\
\hline $\begin{array}{l}\text { Sequelae } \\
\text { present }\end{array}$ & $26(31.7 \%)$ & $12(14.6 \%)$ & $\begin{array}{l}16 \\
(19.5 \%)\end{array}$ & $\begin{array}{l}54 \\
(65.9 \%)\end{array}$ \\
\hline $\begin{array}{l}\text { Sequelae } \\
\text { absent }\end{array}$ & $11(13.4 \%)$ & $9(11.0 \%)$ & $\begin{array}{l}8 \\
(9.8 \%)\end{array}$ & $\begin{array}{l}28(34.1 \\
\%)\end{array}$ \\
\hline Total & $45.1 \%$ & $25.6 \%$ & $29.3 \%$ & $100 \%$ \\
\hline
\end{tabular}

Table 4 - Factors associated with spirometric abnormalities

\begin{tabular}{|c|c|c|c|c|}
\hline & Obstructive & Restrictive & Normal & $\begin{array}{c}\mathrm{P} \\
\text { value }\end{array}$ \\
\hline $\begin{array}{c}\text { Radiological } \\
\text { sequelae }\end{array}$ & 26 & 12 & 16 & 0.596 \\
\hline Smokers & 34 & 11 & 14 & 0.001 \\
\hline $\begin{array}{c}\text { Symptomati } \\
\text { c patients }\end{array}$ & 34 & 15 & 12 & 0.004 \\
\hline
\end{tabular}

Therefore a total of 224 patients were available for study. Of these spirometry data were available for 82 patients. Further analysis was performed in these 82 patients. 


\section{Demographic data}

The age of the patients ranged from 24 to 80 years and mean age was 51.29. $74(90.2 \%)$ were males and $8(9.8 \%)$ were females. 73 patients $(89 \%)$ belonged to low socioeconomic status.

\section{Symptomatology and other characteristics during diagnosis of tuberculosis}

The mean duration of symptoms before diagnosis of tuberculosis was 9.5 weeks +/- 12 weeks .The duration ranged from 1 week to 52 weeks. The initial sputum smear status at diagnosis was scanty in 2 patients $(2.4 \%), 1+$ in 32 patients (39\%), 2+ in 31 patients $(37.8 \%)$ and $3+$ in 17 patients $(20.7 \%) .81(98.8 \%)$ had an outcome of cure or treatment completed at the end of 6 months of category 1 DOTS. One patient had defaulted without completing treatment.5 patients $(6.1 \%)$ had diabetes during diagnosis of tuberculosis.

At 5 years after treatment completion $61(74.4 \%)$ were symptomatic and $21 \quad(25.6 \%)$ were asymptomatic. The symptoms were cough with expectoration in $50(61 \%)$ patients, haemoptysis in $15(18.3 \%)$ patients, and dyspnea in 45 (54.9\%) patients.

Radiological sequelae were present in 54 (65.9\%) patients. Radiological examination at 5 years after completion of antitubercular treatment showed class 1 shadows in $34(41.5 \%)$ patients, class 2 shadows in $14(17.1 \%)$ patients, class 3 shadows in $1(1.2 \%)$ patients and hyperinflation in 14 $(17.1 \%)$ patients.

\section{Addictions}

$59(72 \%)$ patients were smokers 23 (28\%) were nonsmokers. $4(4.9 \%)$ patients had stopped smoking before the diagnosis of tuberculosis. 15 (18.3\%) had stopped smoking after being diagnosed as tuberculosis. $5(6.1 \%)$

\section{Spirometry data}

Spirometry revealed obstructive pattern in 37 patients $(45.1 \%)$, restrictive pattern in 21 patients $(25.6 \%)$. it revealed a mixed pattern or normal results in 24 patients $(29.3 \%)$.

\section{Factors associated with spirometric} abnormalities Analysis of the factors which were associated with

different

spirometric abnormalities was done. Obstructive spirometry was significantly associated with smoking ( $p$ value - 0.001). Out of the 59 smokers 34 had obstructive spirometry, 11 had had restrictive spirometry and 14 had normal pattern. Out of the 23 non-smokers 3 had obstructive spirometry, 10 had restriction and 10 had normal values.

When those with radiological sequelae were analyzed out of 54 patients who had sequelae 26 had an obstructive pattern, 12 had a restrictive pattern and 16 had a normal pattern. Out of the 28 patients who did not have sequelae 11 had an obstructive pattern, 8 had a normal pattern and 9 had a restrictive pattern. There was no statistical significance.

When the chest x-ray shadows were classified the obstructive pattern was present in 16 of 34 patients with class 1 shadows, restrictive pattern in 10 and normal pattern in 8 patients.

Presence of exertional dyspnea in patient 5 years after treatment of tuberculosis correlated significantly with spirometric abnormalities.

\section{DISCUSSION}

Pulmonary tuberculosis can cause parenchymal destruction by up regulation of inflammatory mediators ${ }^{6}$. Fibrosis, bronchiectasis and bronchostenosis which are the sequelae of pulmonary tuberculosis can cause various pulmonary function abnormalities ${ }^{7}$.

Prevalence of airflow obstruction in smear positive pulmonary tuberculosis

In our study abnormal spirometry was detected in $58(70 \%)$ patients. Various studies in the past have analysed changes in pulmonary function before, during and after pulmonary TB treatment. Between $48.7 \%$ and $76 \%$ of patients had pulmonary function abnormalities after completing pulmonary $\mathrm{TB}$ treatment ${ }^{8,9,10}$. SK Verma et al had a conducted a study in Indian population to find out spirometric abnormality in post - pulmonary tuberculosis patients and found that out of 92 patients $36(39.1 \%)$ patients had obstructive airway disease by spirometry criteria 
of which 7 (7.6\%) had reversible phenomena and $29(31.5 \%)$ had irreversible phenomena. 37 (40.2\%) had restrictive pathology and a normal spirometry was seen in $9(9.7 \%)$ patient 11 . The prevalence of airflow obstruction was found to be $30.7 \%$ among those with a history of tuberculosis, compared with $13.9 \%$ among those without a history in another large study in the Latin American polpulation12.

Mechanism of airflow obstruction in tuberculosis patients

In this study we have studied smear positive tuberculosis patients. Smear positive disease indicates higher bacterial load and probably endobronchial disease which has previously been shown to be associated with pulmonary function decline and obstructive defects in lung function ${ }^{13}$. Tuberculosis may affect lung function by pleural changes, bronchial stenosis or parenchymal scarring as stated in the large population based PLATINO trial ${ }^{14}$. Hnizdo et al. has also shown that lung damage in post tuberculous patients the possible mechanisms suggested were bronchial stenosis and lung scarring. They also suggested that tuberculosis increases the activity of the matrix metalloproteinases enzymes, thus contributing to pulmonary damage ${ }^{15}$.

\section{Associated factors in airflow obstruction}

Smoking is an important confounding factor which is present in a significant number of patients in our study.Unlike majority of studies in this aspect we have found obstructive abnormality as predominant. This may be because of the larger number of smokers in the study and the predominant smoking behaviour of continuing smoking even after a diagnosis of tuberculosis. More than half of the study population were smokers in this study. They were having obstructive pulmonary function abnormality. Though we found obstructive abnormality more commonly among smokers, non-smokers also showed significant spirometric abnormalities which were restrictive or mixed pattern. Various other studies have analysed the confounding effects of risk factors like smoking. For example, the PLATINO study revealed that obstructive abnormality remained unchanged after adjusting for factors like childhood respiratory infections, age, smoking, current comorbid illnesses etc. ${ }^{14}$.

In our study there were very few patients with advanced radiological lesions. Radiological emphysema was present in patients. Though around $72 \%$ patients had radiological sequelae most were class 1 changes. But these changes correlated significantly with presence of spirometric abnormalities and presence of persistent respiratory symptoms like dyspnea and cough. Association between moderate and far advanced radiological lesions and lung function abnormalities like reduced PEFR has been reported in some studies ${ }^{15}$. Plit et al has found that the radiographic score at the beginning and after completion of treatment was related to Forced Expiratory Volume in first second ${ }^{16}$. A bronchodilator response is reported to be lesser in post tuberculosis patients compared to other obstructive airway disorders ${ }^{17}$. But it has also been suggested that bronchodilator therapy can be used in treating these people especially those who present with wheezing ${ }^{13}$.

\section{Timing of onset of airway obstructive disease in post TB patients}

The detection of lung function abnormality after onset of tuberculosis was at 5 years in our study. This period has varied in many previous studies ranging upto31 years ${ }^{18}$. Generally the greatest reduction in lung function occurs at 6 months after tuberculosis diagnosis and stabilises by 1 year ${ }^{11}$.

\section{LIMITATIONS}

The limitations of our study include the limited number of patients. Since the follow up was done in a cohort of treated smear positive tuberculosis patients a comparison between normal population could not be done. Most of the tuberculosis patients were smokers which could have had a confounding effect on the parameters studies. Post bronchodilator reversibility was not done which could detect reversible airway obstruction which was more amenable to treatment. 
However this study raises the important issue of respiratory morbidity in post tuberculosis patients even after completion of treatment of tuberculosis. Since COPD is the fourth leading cause of death in the world and tuberculosis the seventh according to $\mathrm{WHO}^{19}$, and both being associated with each other, the proper recognition and treatment of both diseases will be hugely beneficial from a public health point of view.

\section{CONCLUSIONS}

Abnormal spirometry was found in 58 (70\%) patients. Obstructive pattern was the most common abnormality. Restrictive pattern was the main abnormality in nonsmokers. Presence of radiological sequelae correlated with the presence of spirometric abnormality. The obstructive pattern showed significant association with presence of radiologic sequelae, smoking and persistent chest symptoms after completion of ATT.

\section{REFERENCES}

1. World Health Organization. Global TB control: surveillance, planning, financing. WHO Report 2008, Geneva, 2008. Available from http://www.who.int/tb/publications/global _report/2008/

2. World Health Organization. Global Tuberculosis Control-WHO Report 2010. Available from: http://www.who.int/tb/publications/global _report/2010/ (Accessed December 16th, 2010).

3. Mohamed ManjiEmail author, Grace Shayo, Simon Mamuya, Rose Mpembeni, Ahmed Jusabani and Ferdinand Mugusi. Lung functions among patients with pulmonary tuberculosis in Dar es Salaam a cross-sectional study. BMC Pulmonary MedicineBMC series April 2016

4. Global Institute for Chronic Obstructive Lung Disease. Geneva, Switzerland: 2008. [accessed on 17 Sep 2009]. Workshop report: global strategy for diagnosis, management, and prevention of COPD. Available at http://www.goldcopd.org.

5. American Thoracic Society. Standardization of Spirometry, 1994 Update. American Thoracic Society. Am J Respir Crit Care Med. 1995; 152:1107-1136. [PubMed]

6. Dheda K, Booth H, Huggett JF, Johnson MA, Zumla A, Rook GA. Lung remodeling in pulmonary tuberculosis. $\mathrm{J}$ Infect Dis. 2005; 192:1201-9. 10.1086/444545 [PubMed]

7. Curtis JK. The significance of bronchiectasis associated with pulmonary tuberculosis. Am J Med. 1957; 22:894903. 10.1016/0002-9343(57)90025-6 [PubMed]

8. Willcox PA, Ferguson AD. Chronic obstructive airways disease following treated pulmonary tuberculosis. Respir Med. 1989; 83:195-8. 10.1016/S09546111(89)80031-9 [PubMed]

9. Plit ML, Anderson R, Van Rensburg CE, Page-Shipp L, Blott JA, Fresen JL, et al. Influence of antimicrobial chemotherapy on spirometric parameters and proinflammatory indices in severe pulmonary tuberculosis. EurRespir J. 1998; 12:351-6. 10.1183/09031936.98.12020351

[PubMed]

10. Pasipanodya JG, Miller TL, Vecino M, Munguia G, Garmon R, Bae S, et al. Pulmonary impairment after tuberculosis. Chest. 2007 Jun; 131:1817-24. 10.1378/chest.06-2949 [PubMed]

11. Verma SK, Narayan KV, Kumar S. A Study on Prevalence of Obstructive Airway Diseaseamong Post Pulmonary Tuberculosis Patients [Internet]. Pulmon; 2009 [cited 2014 Jan 15

12. Menezes AMB, Hallal PC, Perez-Padilla R, Jardim JRB, Muiño A, Lopez MV, et al., Latin American Project for the Investigation of Obstructive Lung Disease 
(PLATING) Team Tuberculosis and airflow obstruction: evidence from the PLATINO study in Latin America: EurRespir J 2007; 30:1180-1185

13. Canetti G. Present aspects of bacterial resistance in tuberculosis. Am Rev Respir Dis. 1965;92:687-703. [PubMed] [Ref list]

14. Hallett WY, Martin CJ. The diffuse obstructive pulmonary syndrome in a tuberculosissanatorium. . etiologic factors. Ann Intern Med. 1961 Jun 1;54(6):114655.

15. Rajasekharan S, Savitri S, Jeyaganesh D. Post tuberculosis bronchial Asthma. Ind J Tub 2001; 48: 139.

16. Plit ML, Anderson R, Van Rensburg CEJ, Page-Shipp L, Blott JA, Fresen JL, Feldman C. Influence of antimicrobial chemotherapy on spirometric parameters and pro-inflammatory indices in severe pulmonary tuberculosis. EurRespir J 1998; 12: 351-356.

17. Lee JH, Chang JH. Lung function in patients with chronic airflow obstruction due to tuberculous destroyed lung. Respir Med. 2003; 97:1237-1242. [PubMed] [Ref list]

18. Hnizdo E, Singh T, Churchyard GJ. Chronic pulmonary function impairment caused by initial and recurrent pulmonary tuberculosis following treatment. Thorax 2000; 55: 32-38.

19. WHO Fact sheet. The top ten causes of death. 2017. 